\title{
THE CONTROL OF THE DOSAGE OF ANTISERUM IN THE TREAT- MENT OF PNEUMOCOCCAL PNEUMONIA. II. THE CLINICAL APPLICATION OF THE FRANCIS SKIN TEST
}

\author{
BY W. BARRY WOOD, JR. \\ (From the Biological Division of the Department of Medicine, Johns Hopkins Hospital \\ and University, Baltimore)
}

(Received for publication August 23, 1939)

For many years antipneumococcal serum was administered in relatively small doses at intervals of 8 hours and injections were continued until the fever subsided (1). Such a slow method of giving antiserum necessitated a prolonged period of treatment and patients often succumbed to the pneumonia before they had been given adequate quantities of antibody. The importance of administering large doses of serum early in the course of treatment is now well recognized and has recently been reëmphasized by Bullowa (2).

It has been suggested that the ideal method of administering antiserum is to give the entire effective therapeutic dose in a single injection. This has been done by certain investigators with apparent success (3), but the method is highly impractical because, for reasons emphasized in a previous report (4) and illustrated by certain of the cases reported in the present study, it is quite impossible to calculate even roughly the effective therapeutic dose of antiserum for any given patient with pneumonia. To give more than the minimum effective dose only wastes serum and increases the cost of treatment.

Neither the slow method of giving repeated injections of antiserum at intervals of several hours nor the ultra-rapid method of attempting to administer the entire effective dose in a single injection is theoretically sound. In order to determine the optimum amount of antiserum to be given patients with pneumococcal pneumonia it is necessary to employ some method of controlling the dosage of serum based upon the measurement of type-specific antibody circulating in the patient's blood.

Various methods have been advocated in the past, none of which has proved to be entirely satisfactory. The most widely used has been the microscopic agglutination test introduced by Sabin in 1930 (5). Besides minor technical drawbacks which are inherent in any agglutination method
(4), the test may, under certain circumstances, be unreliable as a guide to serum therapy. To illustrate this fact the following case report is briefly presented (see Figure 1):

A 51-year-old Russian laborer with type I pneumonia involving the lower lobe of the right lung was admitted to the hospital on the third day of illness. Blood culture showed 50 colonies of type I pneumococcus per cc. The patient was treated with type I antipneumococcal serum, and an attempt was made to control the dosage of antiserum by the agglutination method. Serum treatment was discontinued as soon as a definitely positive agglutination reaction was obtained, but the temperature remained elevated, and the patient failed to improve in spite of the fact that repeated tests revealed the presence of type I agglutinins in his blood serum. Finally, after 4 days, more antiserum was given and the prompt response which followed indicated clearly that insufficient antibody had been given in the first course of treatment.

The agglutination method cannot be relied upon as a guide to serum dosage because of the fact that agglutinins may be detected in the patient's blood serum, as in the above case, before adequate amounts of antibody have been given (6). Bullowa (7) has attempted to avoid this difficulty by using a roughly quantitative modification of the Sabin method. The quantitative modification appears to be more satisfactory, but even this method has been found occasionally to be unreliable (9).

A "capsule swelling test" based upon the Neufeld "quellung" reaction (8) has also been used by Bullowa and Sharff (9) to follow the antibody content of the blood of patients receiving antipneumococcal serum. Although the test was found to be technically simple, the authors reported that it was no more reliable than the quantitative microscopic agglutination test, both being positive on one occasion in a case of type II pneumonia when bacteremia was present and the disease terminated fatally.

A third method of following serum antibodies 


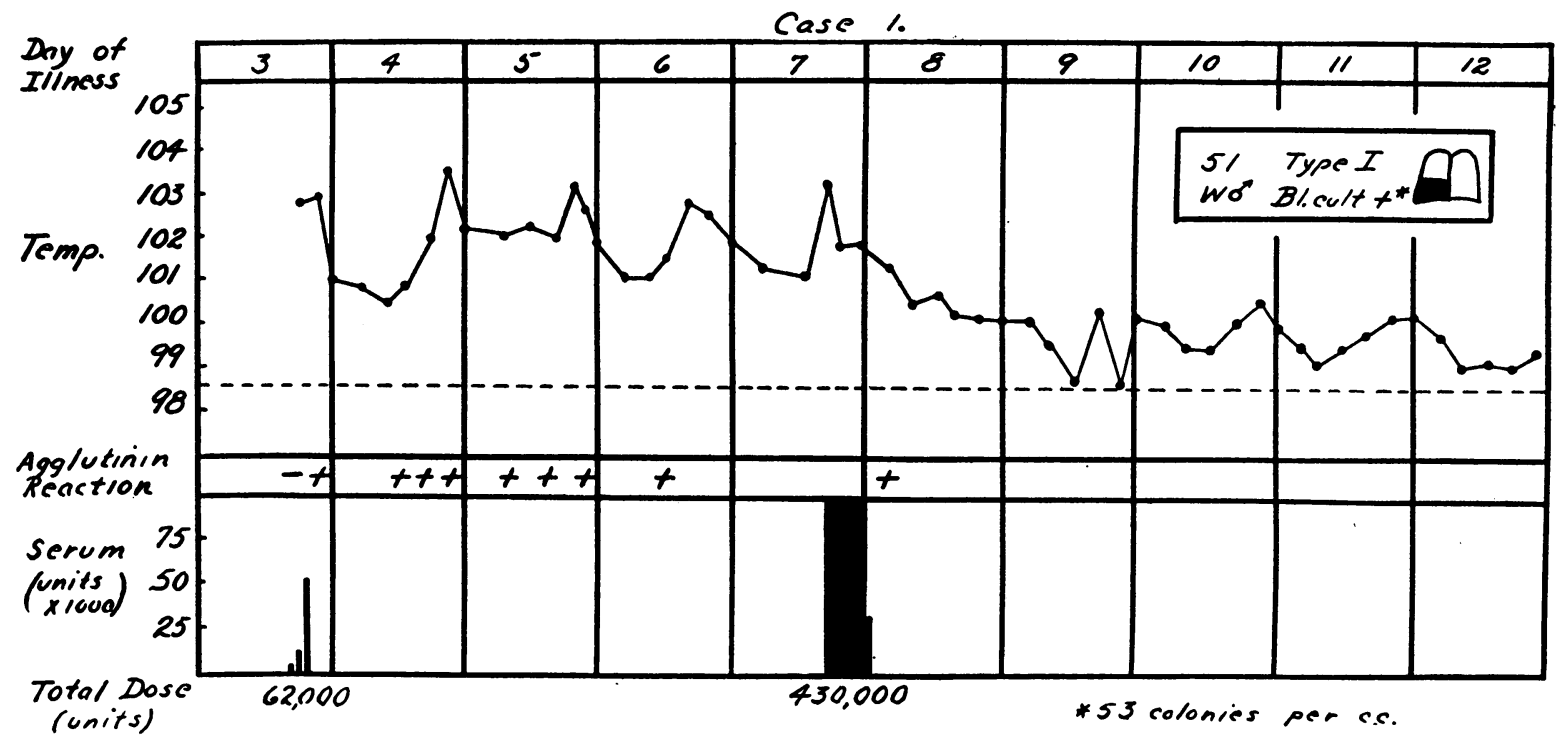

Fig. 1. The Presence of Type-Specific Agglutinins in the Blood Serum of a Patient Inadequately Treated with Anttpneumococcal Serum

is that introduced by Francis in 1933. The mechanism of the skin reaction to pnuemococcal polysaccharides which forms the basis of the Francis skin test has been discussed in a previous publication (4). The present report deals with a clinical study of the skin reaction and its application as a method of controlling serum therapy.

\section{METHODS}

Antisera, polysaccharides and skin tests. The antipneumococcal sera, the preparations of typespecific capsular polysaccharides, and the method of performing and reading the skin tests with polysaccharides have been described in a previous report (4).

Selection of cases. All patients entering the hospital with lobar pneumonia and treated with immune serum were included in the present study. The patients treated were suffering from pneumonia caused by pneumococci of types I, II, III, IV, V, VII and VIII. A skin test with the polysaccharide which corresponded in type to the pneumococcus causing the pneumonia was performed in each case before serum treatment was begun. If the skin reaction was positive at this stage, no attempt was made to use the test as a guide to serum therapy (10).

Control of serum dosage. In all cases where the first skin test was negative, a small initial dose of antiserum (1,000 to 10,000 units) was given intravenously, followed by injections of from 10,000 to 100,000 units $^{1}$ spaced at hourly intervals. The patient's temperature was taken every hour during the period of therapy. A skin test was performed 30 minutes before each injection of antiserum, and as soon as a definitely positive reaction was obtained, the serum therapy was discontinued regardless of the clinical status of the patient. The test was then repeated in one hour and, if still positive, no further therapy was given. Skin tests were performed thereafter at least once a day (and more often in the presence of fever) until recovery was well established. Under no circumstances was serum treatment resumed unless the skin reaction became negative. These rules were adhered to strictly because only by so doing was it thought that the worth of the skin test could be accurately evaluated.

\section{RESULTS}

Limitations of the skin test method. Fiftyseven patients with pneumococcal pneumonia were tested with the polysaccharide corresponding in type to the pneumococcus identified in the sputum; at a time when the disease was apparently still progressing, 5 (or 8.8 per cent) reacted posi-

1 On two occasions larger doses were given in a single injection (see Figure 1 and Figure 2, Case 4). 
tively before receiving any antiserum. All 5 patients were treated with immune serum and all recovered. Since the Francis skin test was positive from the start, it obviously could not be used to control the dosage of antibody. Two of these patients also reacted positively to polysaccharides of other types. The blood sera of 2 of the 5 patients were tested before treatment for the presence of type-specific antibody, one by microscopic agglutination tests, the other by the mouse protection method. No antibodies were detected in either serum. The mechanism of these "false positive" reactions is apparently quite different from that of the reaction to homologous polysaccharide which occurs with recovery from pneumococcal pneumonia, since the latter is always associated with the presence of type-specific antibodies in the blood serum (6).

In agreement with these results, MacLeod, Hoagland and Beeson (10) have recently reported that 12.5 per cent of a series of 104 patients showed positive skin tests before serum had been given. Type-specific agglutinins were not present in the blood serum of any of the 4 patients tested among the positive reactors. None of the patients gave a history of a previous pneumococcal infection and in only 1 case was there a history of any form of cutaneous hypersensitivity. The authors were unable to account for the positive skin reactions in these patients but concluded that they were not associated with the presence of circulating antibodies in the blood serum. They also pointed out that in individuals acutely ill with pneumonia the incidence of positive skin reactions is much lower than among normal individuals who are not suffering from pneumococcal infections $(11,12,13)$.

It should be clearly understood that, if the Francis skin test is to be used as a guide to serum therapy, it must be performed on every patient before serum treatment is begun. The test obviously cannot be used to control serum dosage in patients who react positively from the start. Fortunately, the occurrence of "false positive" reactions is not sufficiently frequent to handicap the method seriously.

D.fficulty was occasionally encountered in reading the skin test, especially in Negro patients. The zone of erythema which surrounds the wheal in a positive reaction is sometimes barely per- ceptible in the melanotic skin unless viewed under a very bright light. Early in the course of the present study it was found impossible to read the Francis test in one extremely dark Negro patient, and the attempt to control the dosage of serum by means of the test had to be abandoned. It was later learned that the zone of erythema could be easily seen in the skin of even the darkest Negroes if the site of injection was examined under the proper light. Thereafter a 100-watt lamp held close to the skin was used in reading all tests and no further difficulty was encountered.

The skin test as a guide to serum therapy. The skin test with type-specific poysaccharides was used to control the dosage of antiserum in the treatment of 51 patients with pneumococcal pneumonia. To simplify presentation, the cases may be grouped as follows:

(1) Uncomplicated pneumonia treated with antiserum. Twenty-four patients ill with uncomplicated pneumonia responded promptly to serum therapy. In every case the Francis skin reaction became positive shortly before or at the time of crisis. In no case did the temperature reach normal before a positive skin reaction was obtained. The temperature charts of 4 representative patients from the group are shown in Figure 2. It will be noticed that in Case 1 the temperature was approximately $104^{\circ}$ when the skin test became positive and serum treatment was stopped. The temperature remained at this level for more than 4 hours before the crisis finally ensued. By using the skin test it was possible to administer antibody rapidly and still conserve antiserum by stopping treatment several hours before crisis. If the temperature chart alone had been used as a guide to serum dosage, 200,000 units of antibody would have been wasted. Case 2 illustrates a similar situation. The patient suffered a thermal reaction to type III rabbit serum, the temperature rising to $107^{\circ}$. After 160,000 units of serum had been given, however, the temperature had fallen to $102.2^{\circ}$ and the skin test became positive. During the next 3 hours the temperature rose gradually to $103^{\circ}$, but since the skin reaction remained positive, no further treatment was given. At the end of 3 hours a crisis occurred, and the patient made an uneventful recovery.

Cases 3 and 4 are included in Figure 2 to em- 


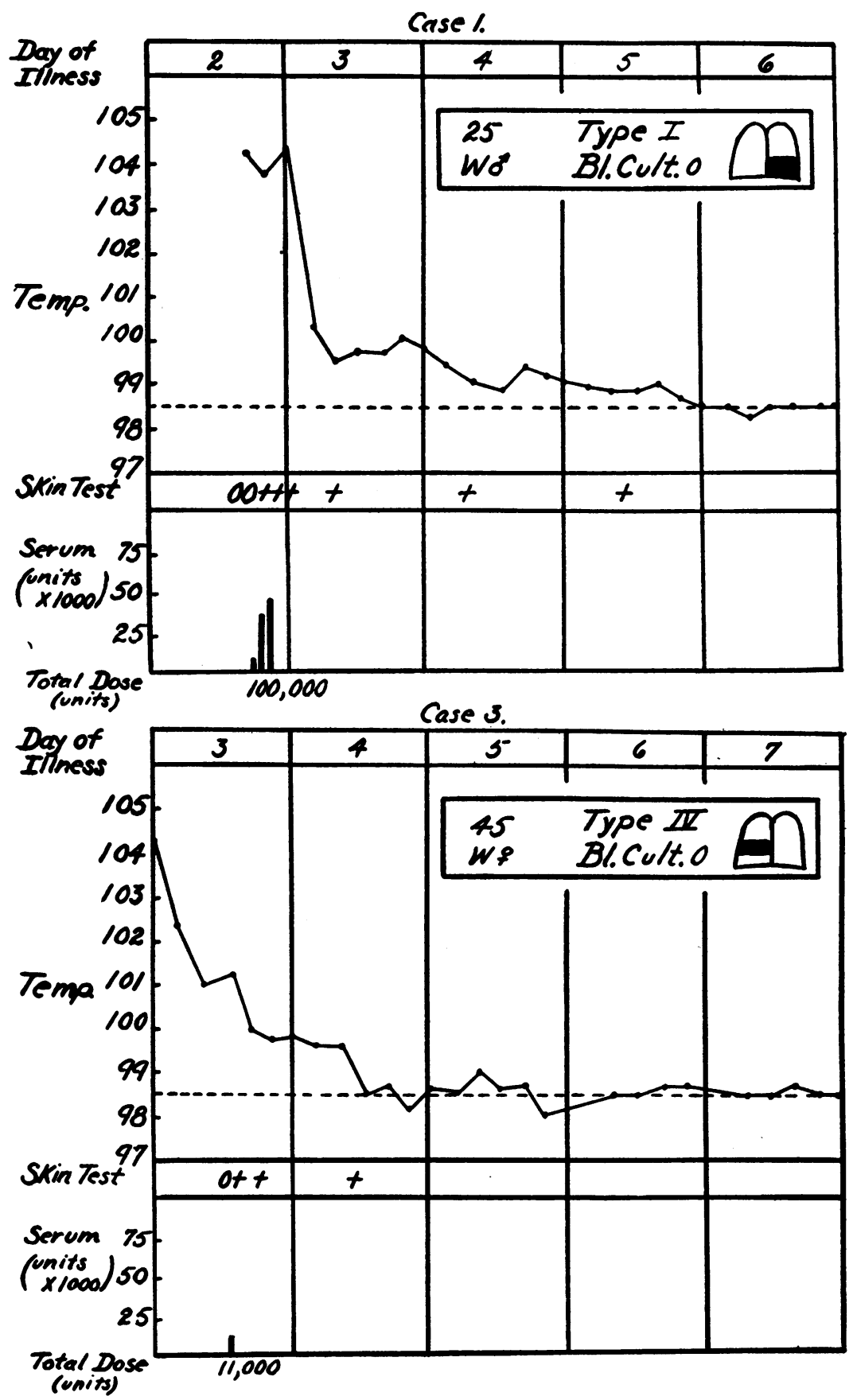

Fig. 2. The francis Skin Test in Uncomplicated Pneumococcal Pneumonia Treated with ANtiserum

(Figure 2 continued on opposite page) 

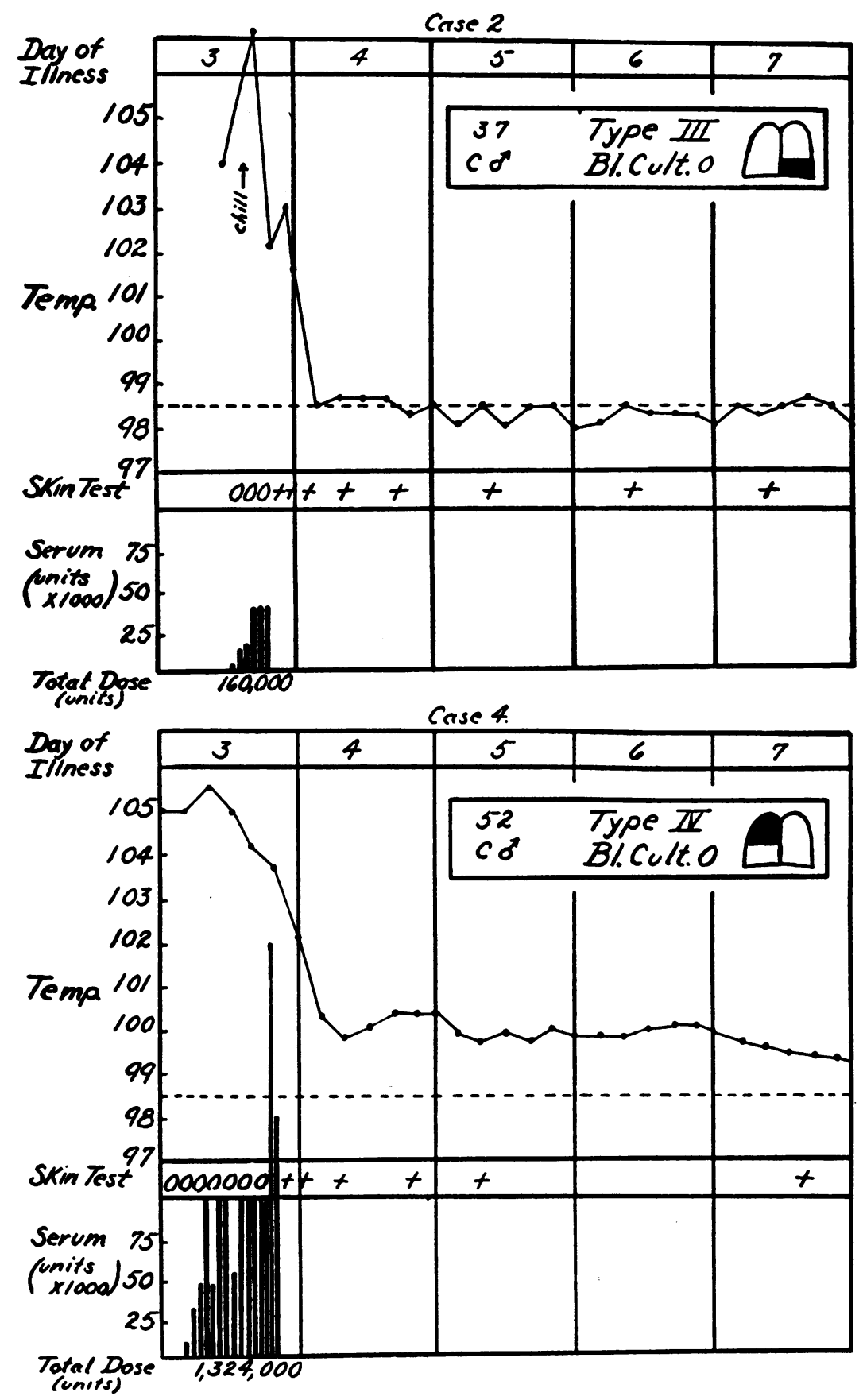
phasize the futility of trying to predict how much serum will be necessary to produce a crisis in any given case of pneumonia. Both patients were suffering from type IV pneumonia without bacteremia and both entered the hospital on the third day of illness with one lobe of the right lung consolidated. The first patient was a 45-year-old white woman, the second a 52-year-old colored man. The white woman required 11,000 units of antibody, the colored man more than $1,300,000$ units. Both recovered promptly. Had the skin test not been used in either of these cases, serum might well have been wasted in Case 3 and given in inadequate amounts in Case 4. It may be argued that the temperature was already falling in Case 3 when treatment was begun and that serum therapy should have been withheld altogether. A fall in temperature, however, cannot always be relied upon as an indication of recovery, for a pseudo-crisis not uncommonly occurs when a pneumonia infection spreads, and fever may be completely absent at times during the course of the severest pneumonia. ${ }^{2}$

It is worthy of note that in Case 3 , where the injection of only a small amount of antibody was required, a skin test done within 30 minutes was found to be strongly positive. This observation indicates that little time is required for the skin to develop its ability to react to polysaccharide once sufficient antibody has accumulated in the blood.

(2) Pneumonia treated with antiserum and sulfapyridine. Eight patients, among the 51 studied, were treated with both sulfapyridine and serum. All recovered promptly, crisis occurring in 7 of the 8 cases at approximately the time that the Francis skin test became positive. The eighth case was of special interest. The patient was first treated with antipneumococcal serum and the temperature failed to fall when the skin reaction became positive. This was later found to be due to the fact that the pnuemonia was caused by more than one type of pneumococcus and, when the infection due to the second organism was treated with sulfapyridine, the fever rapidly subsided.

The temperature charts of 2 of the patients treated with sulfapyridine and antiserum are included in Figure 3. The first patient, ill with

\footnotetext{
2 See Case 3 reported in preceding paper (4).
}

type III pneumonia, failed to respond after 3 days of treatment with sulfapyridine but recovered promptly after receiving adequate amounts of antiserum (judging from the Francis skin test). It has recently been shown that certain patients with pneumococcal pneumonia will not respond to treatment with sulfapyridine alone and should, therefore, be given type-specific serum in addition (14). This fact is well illustrated by the above case. The second patient whose hospital record is summarized in Figure 3 was treated with both serum and sulfapyridine from the start. Crisis occurred shortly after the skin test became positive and the patient's recovery was uneventful. The results obtained in this relatively small group of cases would seem to indicate that the Francis skin test may also be used to determine the optimum amount of antiserum needed for the treatment of patients who have previously received sulfapyridine or other chemotherapeutic agents.

(3) Pneumonia treated with antiserum and complicated by sterile pleural effusion or extrapulmonary pneumococcal infections. The early diagnosis of such complications of pneumonia as sterile pleural effusion and empyema may be greatly facilitated by the use of the skin test with capsular polysaccharides. It is not uncommon for patients treated with antiserum to develop a secondary hyperpyrexia after crisis. The cause of the fever is not always clear, and a decision must be reached immediately as to whether the secondary rise in temperature is due to a spread of the pneumonia or to the presence of an extrapulmonary complication. If the fever is due to the former, more antiserum is indicated; if due to the latter, further antibody given by vein will ordinarily be of no benefit to the patient and will only be wasted. It is well known that in the presence of a sterile pleural effusion, or an extrapulmonary focus of infection involving the pleura, meninges, or endocardium, an excess of typespecific antibody is often already present in the blood serum $(6,15,17)$. To administer more antiserum intravenously under these circumstances is illogical, since even the greatest excess of circulating antibody has been found to exert little, if any, influence upon such complications as empyema, meningitis, and endocarditis. ${ }^{8}$

8 It has been shown by Horsfall, Goodner, and MacLeod (3) that the antibody of rabbit antipneumococcal 

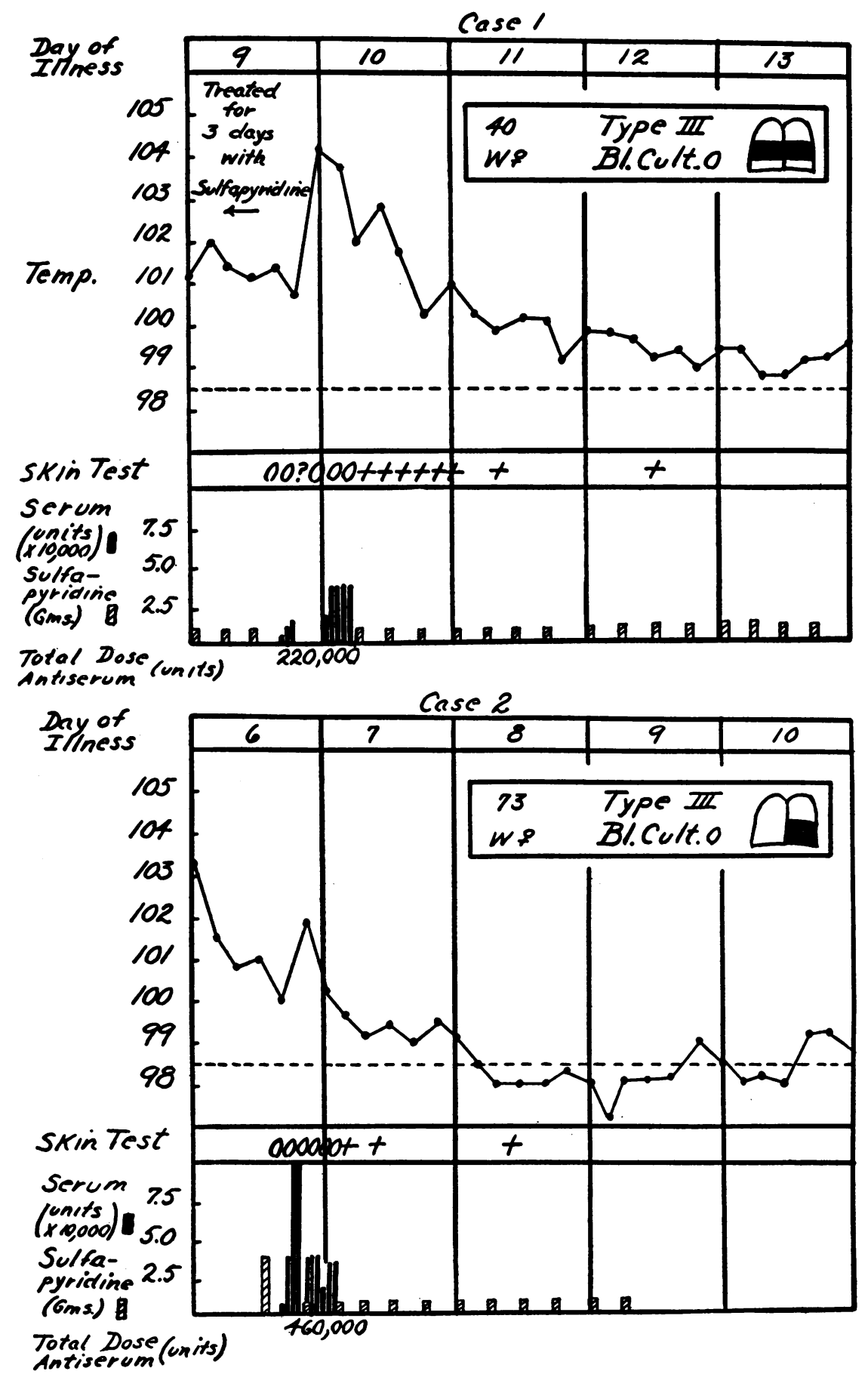

Fig. 3. The Francis Skin Test in Pneumococcal Pneumonia Treated with ANTTSERUM AND SUlfapyridine 

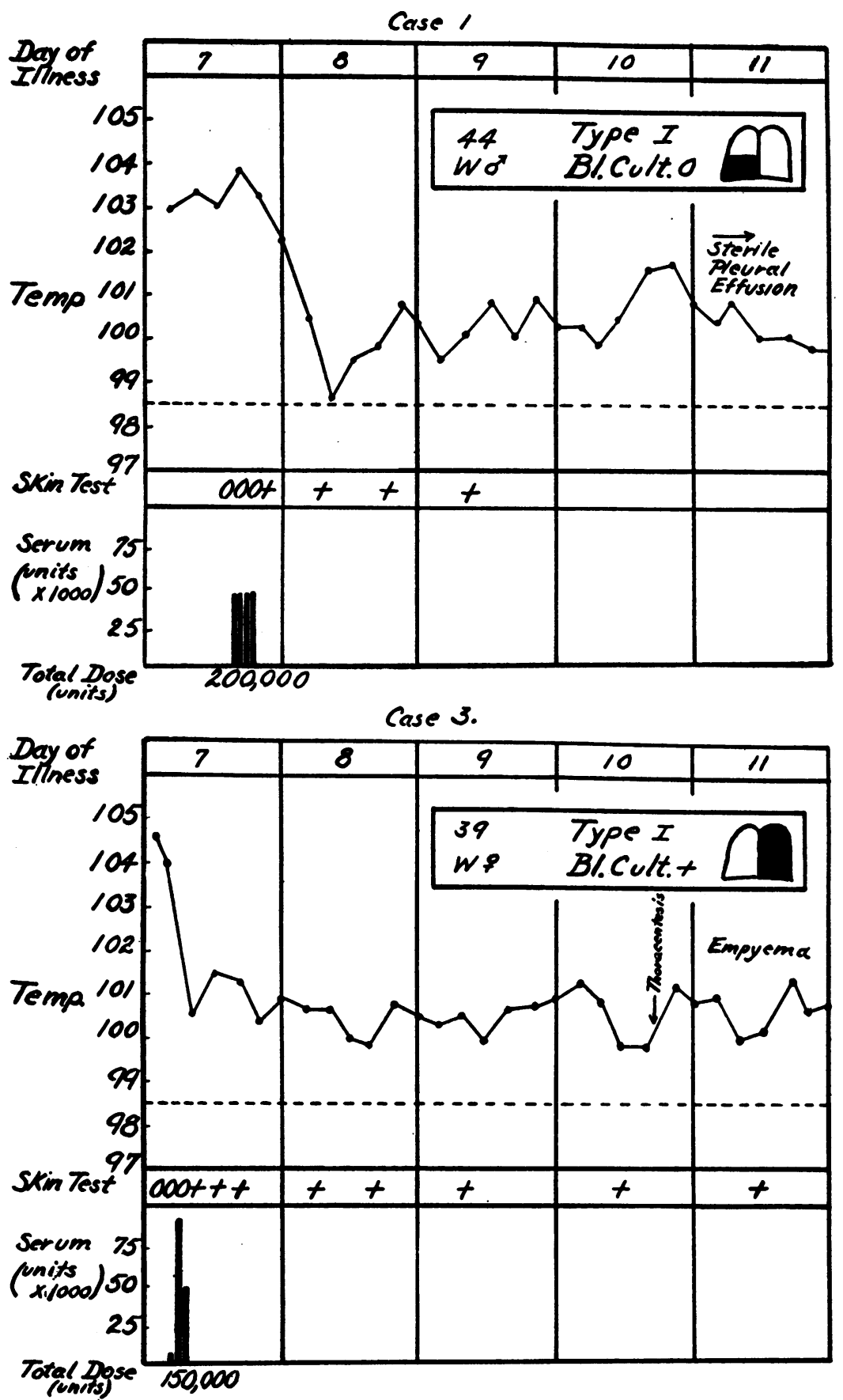

Fig. 4. The Francis Skin Test in Pneumococcal Pneumonia Treated with Antiserum and Complicated by Sterile Pleural

EFFUSION OR EMPYEMA

(Figure 4 continued on opposite page) 

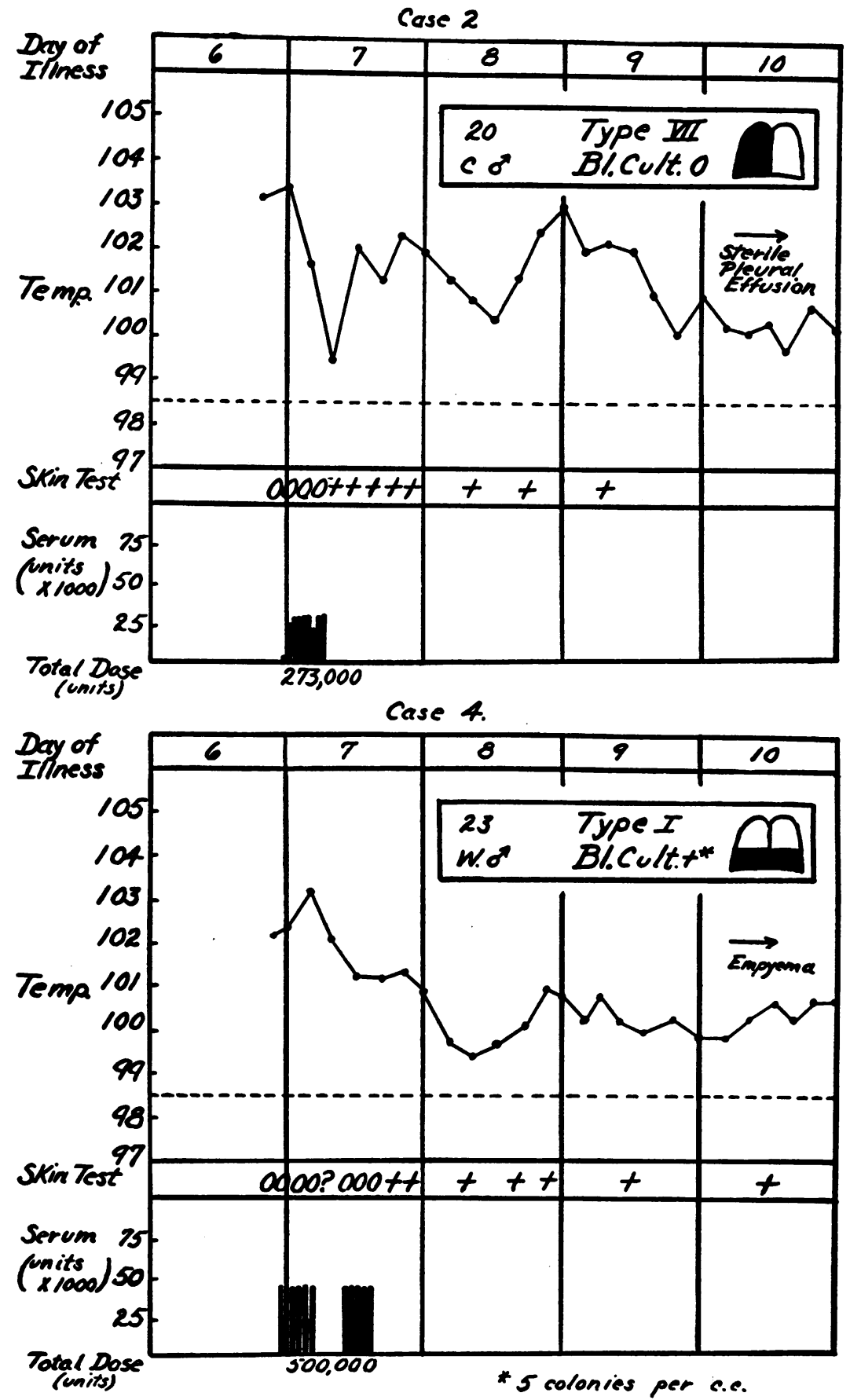
Six patients in the present series developed sterile effusions in the pleural cavity. In every case fever either persisted after the skin test had become positive, or else a secondary rise in temperature occurred after crisis in spite of a persistently positive skin reaction. The positive Francis tests in the presence of continued fever suggested some extrapulmonary complication, and on each occasion this suspicion was confirmed by thoracentesis. Three cases of empyema were also encountered in which the positive skin reaction in the presence of fever suggested the diagnosis. None of the 9 patients was given additional antiserum after the Francis test had become positive, and all 9 recovered. The empyemas were treated by surgical drainage. The results of the skin tests with type-specific polysaccharides in representative cases of pneumonia treated with antiserum and complicated by sterile pleural effusion and empyema are shown in Figure 4.

One instance each of meningitis and endocarditis occurred in the group studied; both are of considerable interest. The first patient (Case 1, Figure 7) showed a positive skin reaction after he had received 300,000 units of type II antibody. A blood culture taken at the time of his admission to the hospital revealed 680 colonies of type II pneumococcus per cc.; a second culture, taken after treatment, was sterile. In spite of persistently positive skin tests, the temperature remained elevated until death. Autopsy revealed a purulent meningitis from which type II pneumococci were isolated in pure culture. Since the patient apparently died of an extrapulmonary focus of infection, it is not surprising that his blood serum contained sufficient antibody to maintain a positive skin reaction.

The second patient entered the hospital suffering from type $\mathrm{V}$ pneumonia with bacteremia and the physical signs of aortic insufficiency (Case 2, Figure 7). She was given 1,180,000 units of type $\mathrm{V}$ antibody and the Francis reaction finally became positive and remained so even in the presence of bacteremia and continued fever. After nearly 3 weeks in the hospital the patient died and at postmortem examination there was found an

serum, due perhaps to its relatively small molecular size $(18,19)$, will penetrate the pleura. In spite of this fact, the use of antipneumococcal rabbit serum instead of horse serum has failed to lower the incidence of empyema (20). acute bacterial endocarditis involving the aortic valve from which was cultured a type $\mathrm{V}$ pneumococcus. Although an old organizing pneumonia was present in the left lower lobe, no pneumococci could be isolated from the lungs. It is noteworthy that in this case the skin reaction to polysaccharide was positive at a time when bacteria were cultivated from the blood stream. According to evidence available at the present time the Francis skin reaction does not become positive in the presence of bacteremia unless the pneumonia is complicated by a pneumococcal endocarditis. Antibodies can seldom be detected in the blood when the pneumococcal infection in the lung is advancing with sufficient rapidity to invade the blood stream. On the other hand, it is well known that the antibody content of the blood serum of both patients and experimental animals with pneumococcal endocarditis may be relatively high $(16,21)$, and it is undoubtedly this fact which explains the positive skin reactions observed in pneumonia complicated by pneumococcal lesions of the heart valves.

It may be concluded from the above results that the Francis skin reaction not only serves as an important aid in the diagnosis of the common complications of pneumonia but also makes it possible to avoid wasting antiserum in cases in which a secondary rise in temperature or a prolonged fever is a disturbing feature.

(4) Relapse of pneumonia following inadequate treatment with antiserum. Secondary hyperpyrexia occurring in serum-treated pneumonia is not uncommonly due to a spread of the pneumonic process following inadequate treatment rather than to the common complications just discussed. The immediate recognition of a flare-up of the pneumococcal infection in the lung is of the greatest importance since the progressing lesion can often be checked only by additional therapy. It has been found that, when treatment has been inadequate, the skin reaction to polysaccharide does not remain positive. In 6 instances in the present series of cases the skin reaction reverted to negative after having become positive during serum therapy. One patient never developed a persistently positive skin reaction in spite of continued serum treatment and finally died (Case 2, Figure 8). A secondary rise in temperature occurred in each of the 5 remaining cases at 

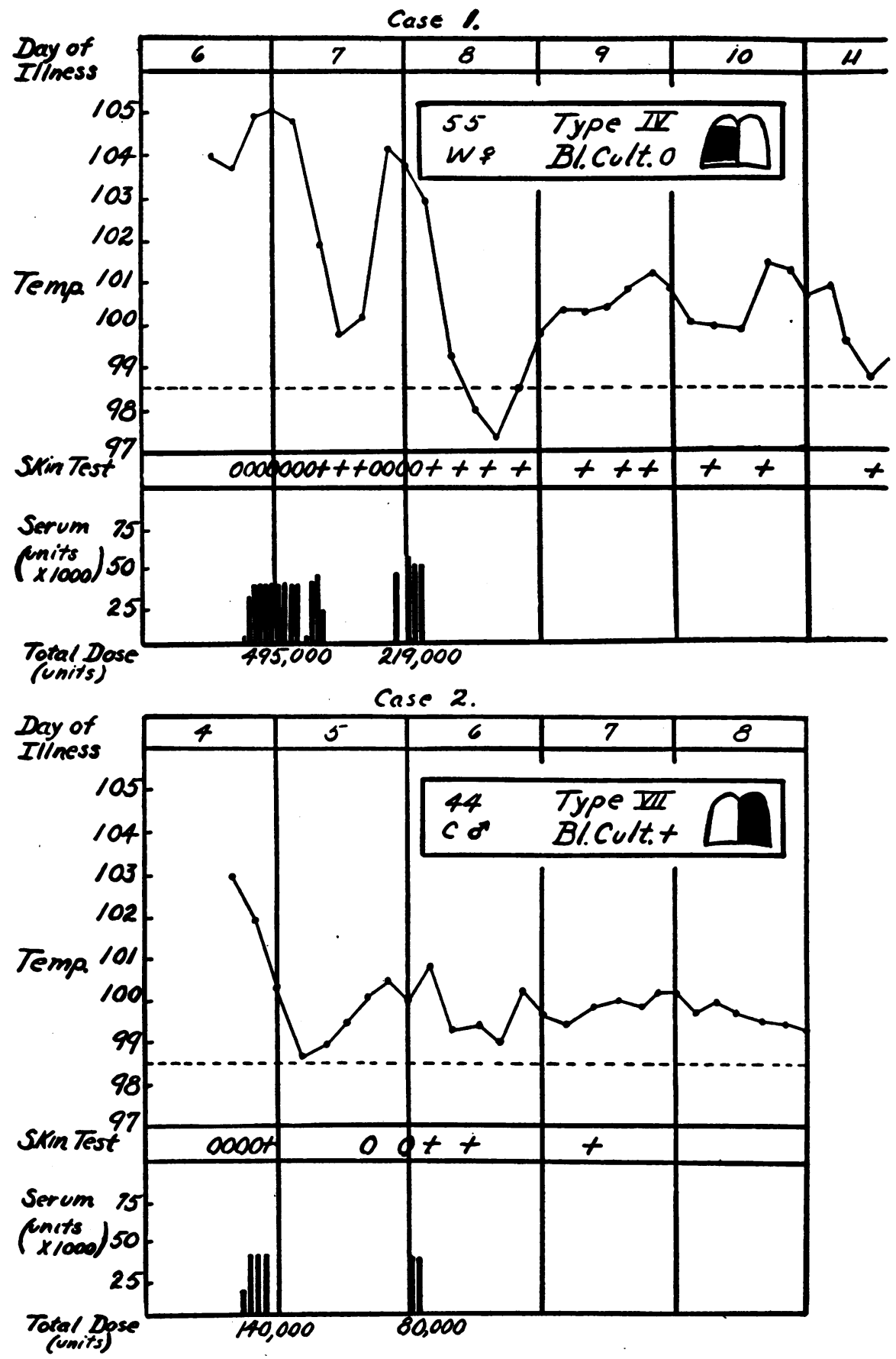

Fig. 5. The Francis Skin Test in Pneumococcal Pneumonia Requiring More than One Course of Treatment with ANTiserum 
the time when the skin reaction became negative, and all 5 patients were given more antiserum. Following the second course of treatment the skin reaction again became positive and the fever subsided. Four of the 5 patients recovered; the clinical course of the pneumonia in 2 of these cases is summarized in Figure 5. The fifth patient finally died in uremia (Case I, Figure 8), and his record will be referred to presently.

These results would seem to confirm the conclusion reached by Francis that a negative skin reaction invariably indicates further serum therapy. By the use of the skin test with type-specific polysaccharides it is possible to distinguish between fever due to an extrapulmonary complication and that due to a progression of the pneumonic infection in the lung. If the fever is caused by the former, the skin reaction remains positive; when due to the latter, it becomes negative. To be able to make this distinction is of practical significance, for although the usual complications of pneumonia are unaffected by continued serum treatment, advancing pneumonia should be controlled immediately by further specific therapy.
(5) Patients with pneumonia who failed to respond to treatment with antiserum. Six patients among the 51 studied failed to survive in spite of intensive treatment with antipneumococcal serum. Their hospital records are summarized in Figures 6, 7, and 8. The first 2 patients were critically ill with bacteremia when admitted to the hospital and neither received sufficient antibody during the short period of treatment to influence the course of the pneumonia. The Francis skin test never became positive in either case and both patients died within 20 hours. The third and fourth patients (Figure 7) died with pneumococcal meningitis and endocarditis respectively; the essential features of their illnesses have already been discussed. The last 2 cases are of particular interest since in both the skin reaction became positive after treatment, although both patients died and neither seemed to be suffering from any form of pneumococcal complication. The first patient, 68 years of age (Figure 8 , Case 1), entered the hospital on the fourth day of a type I pneumonia with bacteremia. After he had been given a total of 650,000 units of type I antibody, his Francis skin test remained

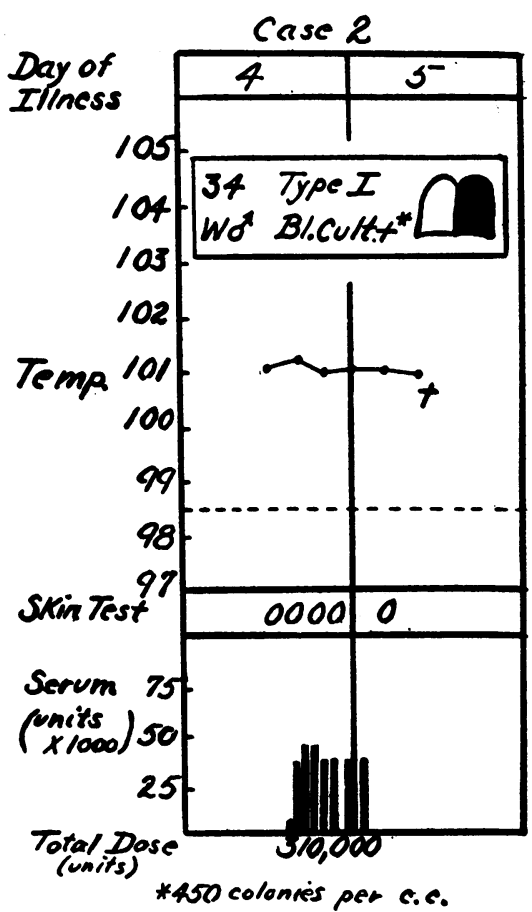

Fig. 6. The Francis Skin Test in Fatal Pneumococcal Preumonia Treated WITH ANTISERUM 


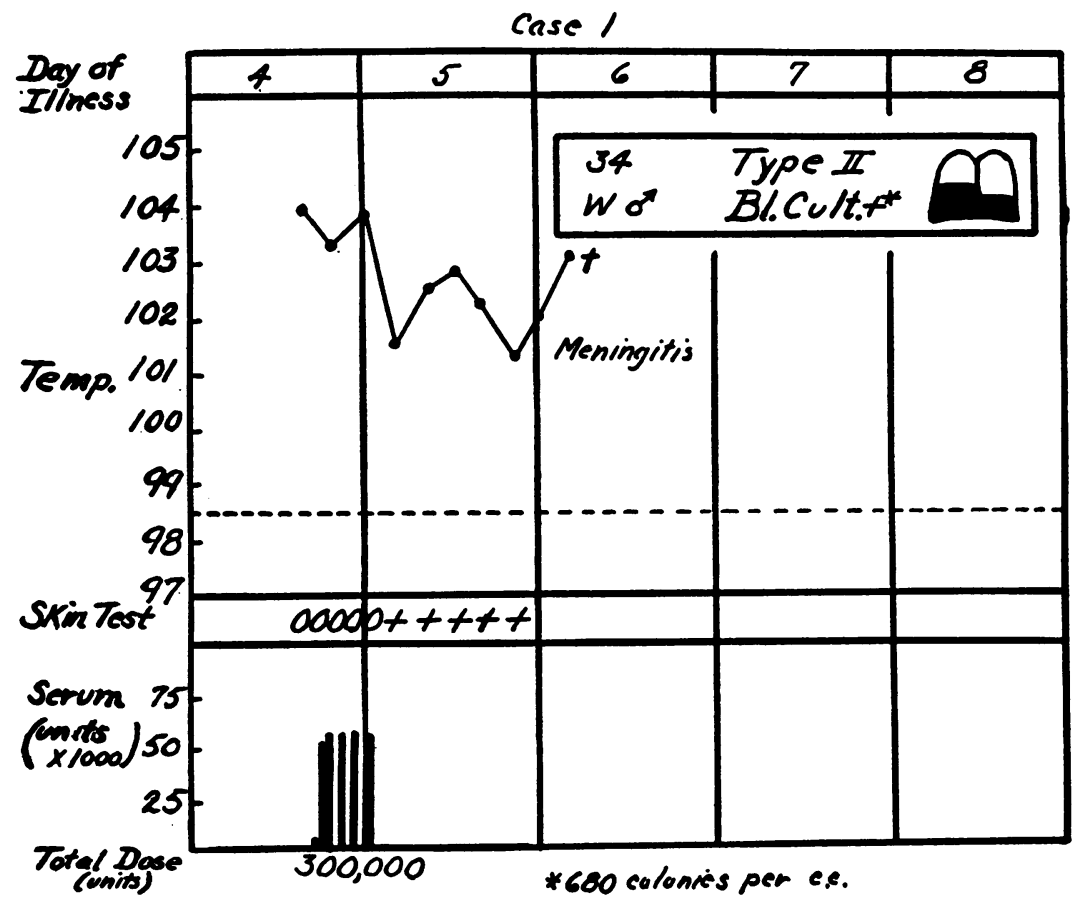

Crese 2.

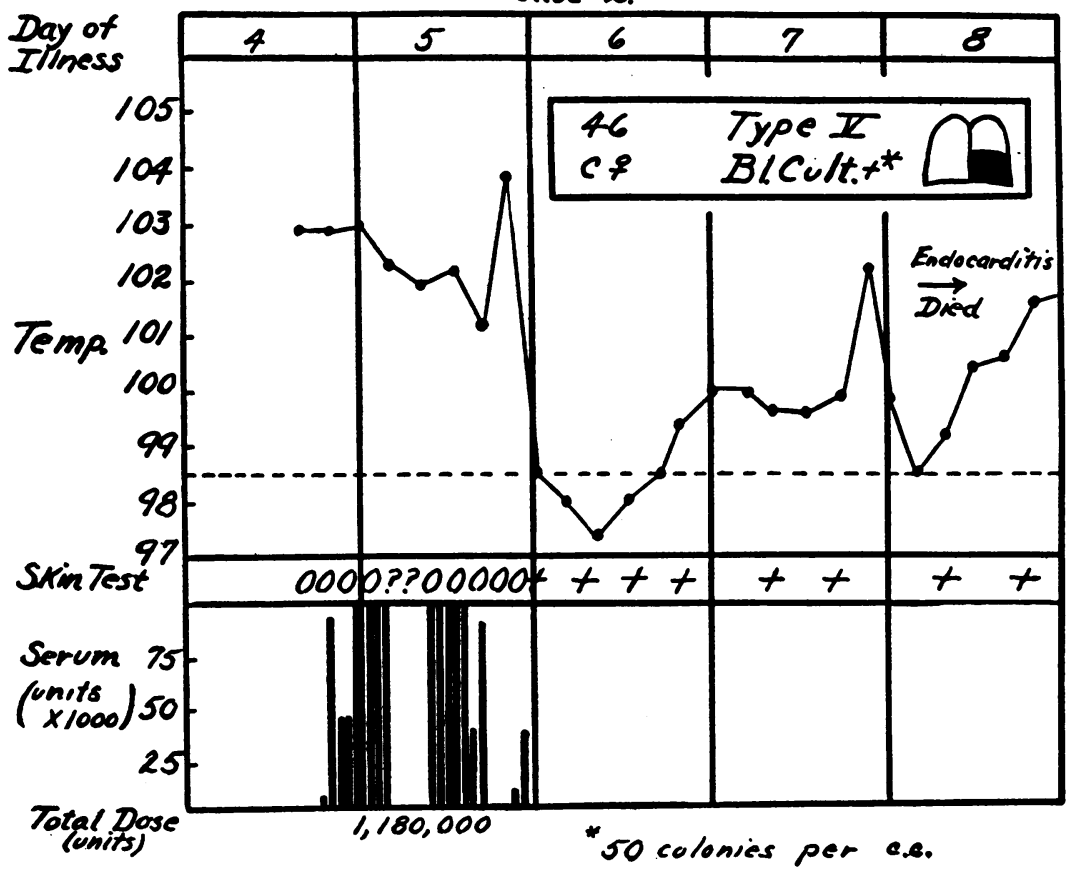

Fig. 7. The Francis Skin Test in Fatal Pneumococcal Pneumonia Treated with Antiserum and Complicated by Meningitis or Endocarditis 
positive, his temperature fell to $100^{\circ}$ and he seemed to be making a good recovery. He was, however, a diabetic with marked hypertension and he finally developed signs of uremia and died on the eighth day of illness. Careful examination of the lungs at autopsy revealed that no pneumococci were present in the alveolar exudate, and the cultures from both lungs and from the blood were sterile. The terminal hyperpyrexia suggested a spread of the pneumonia in spite of the positive skin tests, but the findings at autopsy indicated that the pneumococcal infection had been well controlled and that the patient probably succumbed to the complicating uremia. The second patient was 81 years of age (Figure 8, Case $2)$, and although her skin test became positive several times following serum therapy, it reverted to negative after a few hours on each occasion and remained negative at the time of death. Terminally, the non-protein nitrogen rose to 160 mgm. per cent and, as in the previous case, uremia seemed to be an important factor in the final outcome. Autopsy, however, showed that the pneumonia had not been completely controlled since viable pneumococci were still present in large numbers in the lungs.

Even in the fatal cases of pneumonia the Francis skin test proved to be a reliable guide to serum therapy. Only when death was apparently due to some complication, which would not have been benefited by further serum treatment, did the skin reaction remain positive. Patients dying of pneumonia which was obviously uncontrolled by antibody therapy showed negative skin reactions at the time of death.

\section{DISCUSSION}

The need for a practical method of controlling the dosage of antiserum in the treatment of pneumonia is clearly shown by the wide variations in the total amount of antibody which was needed to treat effectively the individual patients encountered in the present study. The effective therapeutic dose of antibody ranged from 11,000 to $1,983,000$ units. Long experience with antipneumococcal serum in the past has shown that the amount of antibody needed to treat a patient with pneumonia depends in general upon the age of the patient, the day of illness, the type of pneu- mococcus involved, the extent of the pulmonary lesion, and the presence or absence of bacteremia, pregnancy, or a serious complicating disease (22). Although these criteria determine roughly the amount of antiserum the average patient will need, they cannot be applied to any individual case, and therefore are of limited practical value.

During the past year, sulfapyridine has been found to be a very effective drug for controlling pneumococcal infections. Although the use of sulfapyridine in the therapy of pneumonia will undoubtedly decrease the need for type-specific antiserum, it has already been shown (14) that not all patients with pneumococcal pneumonia will respond to treatment with the drug alone. In the drug-refractory cases immune serum should be administered as an adjunct to chemotherapy, and it is only reasonable to suppose that the doses of antiserum needed may be quite different from those required for comparable patients treated with serum alone. The accepted criteria for estimating the average effective therapeutic dose of antibody are based upon past experience with antipneumococcal serum and probably do not apply to patients who have previously been treated with sulfapyridine. It is doubly important, therefore, that some method of controlling the dose of immune serum be employed in the treatment of patients receiving both immunoand chemotherapy.

The Francis skin test may be regarded as a relatively crude method of detecting the presence of type-specific antibodies in the patient's blood. Circulating antibodies can invariably be demonstrated by standard serological methods when, during the course of pneumonia, the skin reaction becomes positive ( 6$)$. On the other hand, the skin reaction may be negative when circulating antibodies are present $(4,6)$ since a relatively high titer of antibody must accumulate in the blood before the skin will react to the homologous polysaccharide (4). The question at once arises as to whether such a crude test for antibodies will serve as a reliable guide for serum therapy. This can best be answered by the following analysis of the present study of 51 cases of pneumococcal pneumonia in which the treatment with specific antiserum was controlled by the Francis skin test.

(1) A positive skin reaction to pneumococcal polysaccharide was obtained a few hours before 

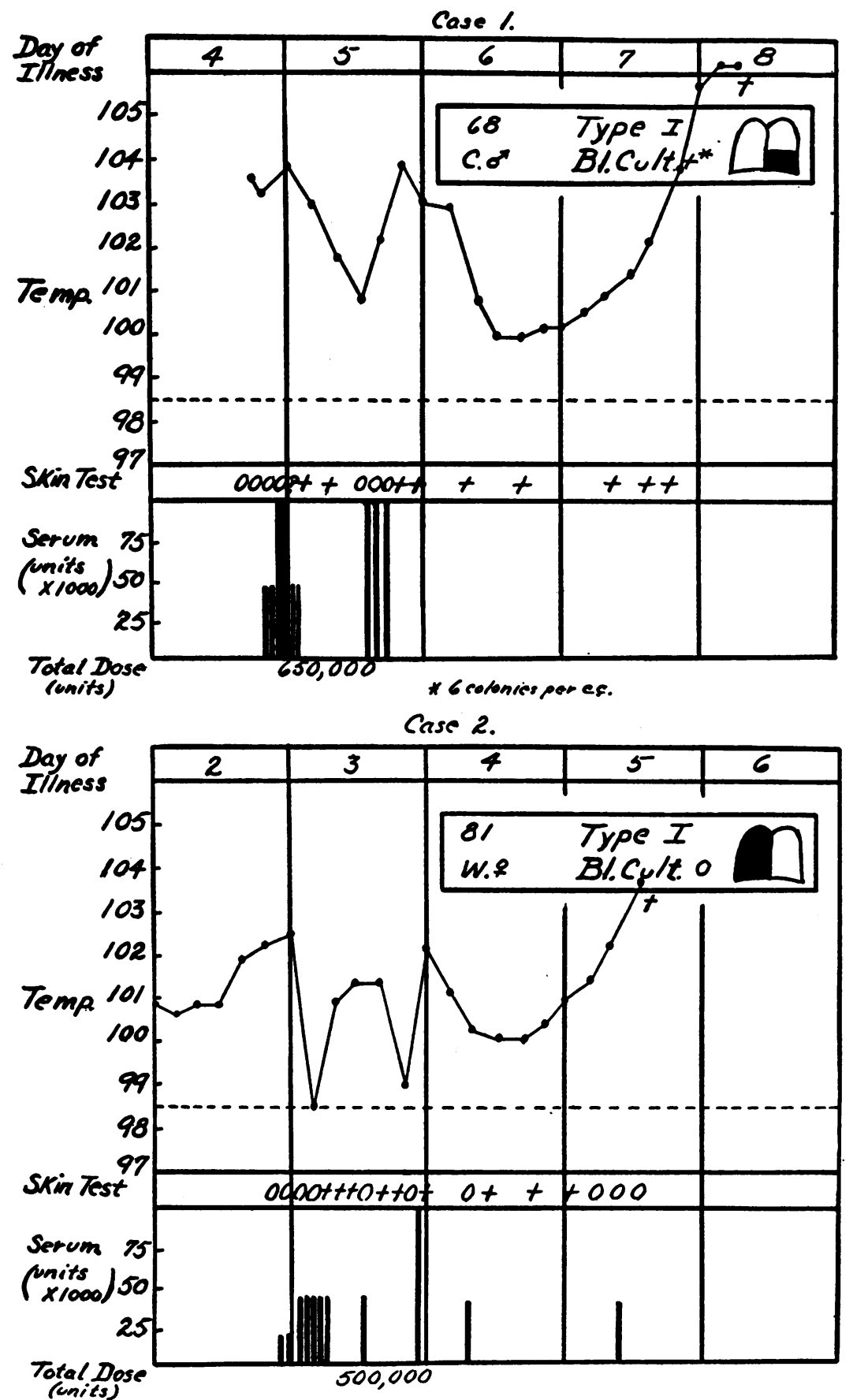

Fig. 8. The Francis Skin Test in Fatal Pneumococcal Pneumonia Complicated by Renal Insuffictency 
or during crisis in every case where recovery occurred without complication.

(2) All patients whose Francis skin tests became positive and remained positive recovered without further specific therapy except 2 patients who died of pneumococcal meningitis and endocarditis respectively.

(3) Every patient who failed to develop a positive skin reaction died.

(4) Once positive, the skin reaction remained so in all but 6 cases. Four patients reacted positively after further treatment and recovered promptly; 2 died, one never again developing a persistently positive reaction in spite of continued therapy, the other dying in uremia after the skin reaction had become positive. Autopsy performed upon the last patient revealed that the pneumonia had been well controlled as evidenced by the fact that no viable pneumococci could be recovered from the lungs.

(5) Among 6 patients who died, 3 showed positive reactions shortly before the time of death. One was the patient just referred to who died in uremia; the other 2 died with meningitis and endocarditis.

(6) In all cases where fever persisted in the presence of a positive skin reaction there was subsequently demonstrated either a sterile pleural effusion or an extrapulmonary pneumococcal infection of the pleura, meninges, or endocardium. Such complications are known to be little affected by continued serum therapy.

It is concluded from the results of the present study that the Francis skin test serves as a reliable aid in determining the optimum amount of antibody needed in the treatment of pneumococcal pneumonia. Its use not only makes it possible to treat patients intensively without wasting antiserum, but also aids in the diagnosis of complications and gives valuable information regarding prognosis. The test has been found to be a satisfactory guide to the dosage of antibody in the treatment of patients given both serum and sulfapyridine as well as those given serum alone.

\section{SUMMARY}

1. Fifty-one patients with lobar pneumonia caused by pneumococci of types I, II, III, IV, V, VII, and VIII were treated with antipneumo- coccal serum. The dosage of antibody administered in each case was controlled by frequent skin tests with the homologous pneumococcal polysaccharide (Francis skin test).

2. Five patients reacted to the polysaccharide before antiserum had been given. In none of these cases could the Francis skin test be used as a guide to serum therapy.

3. The amount of antibody required to control the pneumonia in the cases studied varied from 11,000 to $1,983,000$ units.

4. Use of the Francis skin test made it possible to treat each patient intensively without wasting antiserum.

5. In every case in which a crisis occurred the Francis skin reaction became positive several hours before or during the fall in temperature.

6. The skin test served as a valuable aid in the early diagnosis of the complications of pneumonia. In every case in which fever persisted in the presence of a positive skin reaction there was subsequently demonstrated pleurisy with effusion, empyema, meningitis or endocarditis.

7. No patient who failed to develop a positive skin reaction survived the pneumonia. Three patients who died reacted positively shortly before death; 2 died of pneumococcal complications, and the third died of uremia, no evidence of active pneumonia being found at autopsy.

8. The Francis skin test was also found to be of value in determining the optimum dosage of antibody in the treatment of patients who had previously received sulfapyridine.

\section{BIBLIOGRAPHY}

1. Cole, R. I., Treatment of acute lobar pneumonia. Nelson's Loose-Leaf Living Medicine, 1920, 1, 268.

2. Bullowa, J. G. M., Serum therapy of the pneumococcic pneumonias. Penn. Med. J., 1938-39, 42, 17.

3. Horsfall, F. L., Jr., Goodner, K., and MacLeod, C. M., Antipneumococcus rabbit serum as a therapeutic agent in lobar pneumonia. II. Additional observations in pneumococcus pneumonias of 9 different types. N. Y. State Med. J., 1938, 38, 245.

4. Wood, W. B., The control of the dosage of antiserum in the treatment of pneumococcal pneumonia. I, A study of the mechanism of the skin reaction to type specific polysaccharide. J. Clin. Invest., 1940, 19, 95. 
5. Sabin, A. B., The microscopic agglutination test in pneumonia; its application to rapid typing and control of serum therapy. J. Infect. Dis., 1930, 46, 469.

6. Francis, T., Jr., The value of the skin test with typespecific capsular polysaccharide in the serum treatment of Type I pneumococcus pneumonia. J. Exp. Med., 1933, 57, 617.

7. Bullowa, J. G. M., The Management of the Pneumonias. Oxford University Press, New York, 1937.

8. Neufeld, F., Ueber die Agglutination der Pneumokokken und ûber die Theorieen der Agglutination. Ztschr. f. Hyg. u. Infektionskr., 1902, 40, 54.

9. Bullowa, J. G. M., and Sharff, J., Quantitative capsule swelling tests in blood serum of pneumonia patients. J. Infect. Dis., 1937, 61, 55.

10. MacLeod, C. M., Hoagland, C. L., and Beeson, P. B., The use of the skin test with type specific polysaccharides in the control of serum dosage in pneumococcal pneumonia. J. Clin. Invest., 1938, 17, 739.

11. Finland, M., and Sutliff, W. D., Specific cutaneous reactions and circulating antibodies in the course of lobar pneumonia. I. Cases receiving no serum therapy. J. Exp. Med., 1931, 54, 637.

12. Rogers, E. S., and Wagner, H. C., Relation between skin reactions to specific carbohydrate type I pneumococcus and human blood groups. Proc. Soc. Exp. Biol. and Med., 1935, 33, 249.

13. Alston, J. M., and Lowdon, A. S. R., Studies of the skin reactions to the specific soluble substances of pneumococcus Types I and II. Brit. J. Exp. Path., 1933, 14, 1.

14. Long, P. H., and Wood, W. B., Observations upon the experimental and clinical use of sulfapyridine. II. The treatment of pneumococcal pneumonia with sulfapyridine. Ann. Int. Med., 1939, 13, 487.

15. Finland, M., Immunological reactions of pneumonic pleural fluids. J. Exper. Med., 1932, 55, 169.

16. Lord, F. T., and Parsons, E. L., Certain aspects of mouse protection tests for antibody in pneumococcus pneumonia. J. Exp. Med., 1931, 53, 151.

17. Finland, M., Brown, J. W., and Rauh, A. E., Treatment of pneumococcic meningitis; study of 10 cases treated with sulfanilamide alone or in various combinations with specific antipneumococcic serum and complement including six recoveries. New England J. Med., 1938, 218, 1033.

18. Goodner, K., Horsfall, F. L., Jr., and Bauer, J. H., Ultrafiltration of Type I antipneumococcal serum. Proc. Soc. Exp. Biol. and Med., 1936, 34, 617.

19. Heidelberger, M., and Peterson, K. O., The molecular weight of antibodies. J. Exp. Med., 1937, 65, 393.

20. Wood, W. B., The treatment of pneumococcic pneumonia with concentrated antipneumococcic rabbit serum. J. A. M. A., 1939, 113, 745.

21. Wadsworth, A. B., A study of the endocardial lesions developing during pneumococcal infections in horses. J. Med. Research, 1919, 39, 279.

22. Lord, F. T., and Heffron, R., Pneumonia and serum therapy. The Commonwealth Fund, New York, 1938. 